\title{
A new methodology for computing birds' 3D home ranges
}

\author{
Alessandro Ferrarini ${ }^{1}$ (D), Giuseppe Giglio ${ }^{1}$, Stefania Caterina Pellegrino ${ }^{1}$, Anna Grazia Frassanito² \\ and Marco Gustin ${ }^{1 *}$
}

\begin{abstract}
Background: So far, studies of avian space use are mostly realized in 2D, with the vertical dimension ignored. We propose here a new, relatively simple and computationally reasonable method for the estimation of volumetric (i.e. 3D) avian home ranges.

Methods: Through accurate GPS data-loggers, we collected 25,405 GPS points on Lesser Kestrels' (Falco naumanni) space use during the nestling period in one main colony in Italy. We applied our 3D home range estimator to the whole GPS dataset, and also separately to diurnal and nocturnal GPS points.

Results: The 3D colony home range resulted equal to $28.12 \mathrm{~km}^{3}$. By considering daytime and night-time separately, the volumetric home ranges resulted considerably different.

Conclusions: Our 3D home range estimator, because of its intuitive and straightforward properties, can easily capitalize on the datasets offered by modern biotelemetry (data-loggers, light detection and LIDAR sensors) and enhance conservation strategies for mitigating anthropogenic impacts on bird species. Its applications embrace, but are not limited to, more accurate estimates of collision risk with power lines, aircrafts and wind farms, and increased knowledge of birds' space requirements in order to persist in their distribution areas.
\end{abstract}

Keywords: Avian space use, Biotelemetry, GPS data-loggers, Vertical dimension, Volumetric home range

\section{Background}

After Burt (1943) home range is defined as "that area traversed by an individual in its normal activities of food gathering, mating, and caring for young". Since then, home range estimators have been constantly upgraded to take advantage of the increasing size and accuracy of available datasets (Hebblewhite and Haydon 2010). Tracey et al. (2014) first emphasized the inadequacy of existing modelling techniques to capitalize on threedimensional datasets, thus constraining estimates of animal space use to biologically unrealistic 2D home ranges, and proposed a 3D kernel density estimator of animal home ranges using biotelemetry data. Their estimator, although very elegant, is likely to be mathematically

\footnotetext{
*Correspondence: marco.gustin@lipu.it

${ }^{1}$ Conservation Department, LIPU - BirdLife (Lega Italiana Protezione

Uccelli), Via Udine 3/a, 43122 Parma, Italy

Full list of author information is available at the end of the article
}

inaccessible for most biologists and ecologists, and thus at risk of being used as black-box approach. In addition, it is computationally very expensive relative to simpler, lower-dimensional methods (Tracey et al. 2014).

We propose here an alternative, simpler and more intuitive methodology for the estimation of birds' 3D home ranges. The 3D home range estimator proposed here, because of its relatively-simple, intuitive and computationally-accessible properties, can easily capitalize on the datasets offered by modern biotelemetry (data-loggers, light detection and lidar sensors; Wang et al. 2010) and enhance conservation strategies for mitigating anthropogenic impacts on bird species. We believe that these properties may facilitate its adoption by biologists and ornithologists.

As a case study, we applied our 3D estimator to the Lesser Kestrels' (Falco naumanni) colony of Gravina in Puglia (Apulia region, Southern Italy), that presents the highest number of breeding Lesser Kestrels in Italy 
(in 2013, about 2600 Lesser Kestrels; Gustin et al. 2013) and the most elevated density of Lesser Kestrels in urban areas worldwide. Lesser Kestrel is a colonial falcon breeding in holes and fissures of historic buildings within towns and villages, or in abandoned farm houses in the countryside (Negro and Hiraldo 1993). It is present among Annex I species of EU Wild Birds Directive (2009/147/EEC) and its important breeding habitats have been designated as Special Protection Areas of the Natura 2000 Network in Italy, Spain, Portugal and Greece. The study area (Fig. 1) lies within the Special Protection Area "Murgia Alta" IT9120007 which covers the Alta Murgia National Park and is included in the IBA (Important Bird Area) "Murge". The study area presents partially-suitable land cover composition and spatial arrangement of foraging habitats for Lesser Kestrels (Gustin et al. 2017a; Ferrarini et al. 2018), which mainly consist of pseudo-steppes and, secondarily, non-irrigated arable lands (Gustin et al. 2014a).

\section{Methods}

Five Lesser Kestrels were surveyed from June 15th to July 8th 2013, corresponding to the nestling period, using TechnoSmart GiPSy-4 data-loggers (23 $\mathrm{mm} \times 15 \mathrm{~mm} \times 6 \mathrm{~mm}, 5 \mathrm{~g}$ weight), that provided information about date, time, latitude, longitude, altitude (m, a.s.l.) and instantaneous speed. Birds were captured and fitted with data loggers at their nest boxes when they were delivering food to their nestlings. All devices were tied dorsally to the base of two central tail feathers (Additional file 1: Fig. S1). The percentage weight of the devices in relation to tracked Lesser Kestrels was less than $4 \%$ for all of the individuals (Additional file 2: Table S1). The application of transmitters did not take more than 15 min, and on no occasion it had visible deleterious effects on the studied birds. To download the data from the data-loggers, birds were recaptured at their nest boxes after batteries were exhausted.

During the monitoring period, $92.52 \%$ of GPS points (i.e. 23,504 points) resulted linked to $6-8$ satellites. In these favorable conditions, errors associated to the measurement of flight heights were in the order of $\pm 4-6 \mathrm{~m}$ (TechnoSmart 2012). Approximately 5.83\% of GPS fixes (i.e. 1481 points) received signals from 5 satellites. We discarded 420 GPS points (i.e. 1.65\% of GPS fixes), linked to less than 5 satellites, because measurement errors of flight heights were in the order of $\pm 20-25 \mathrm{~m}$ (TechnoSmart 2012). GPS data were imported into GIS and superimposed on the terrain elevation of the study area digitized by the authors at 1:2000 scale from available topographic maps of Apulia Region (Additional file 1: Fig. S2).

In the first step of our methodological framework, flight height above ground level (in meters; $H$ a.g.l. hereafter) was calculated for each GPS point by subtracting terrain elevation a.s.l. from altitude a.s.l. provided by data-loggers.

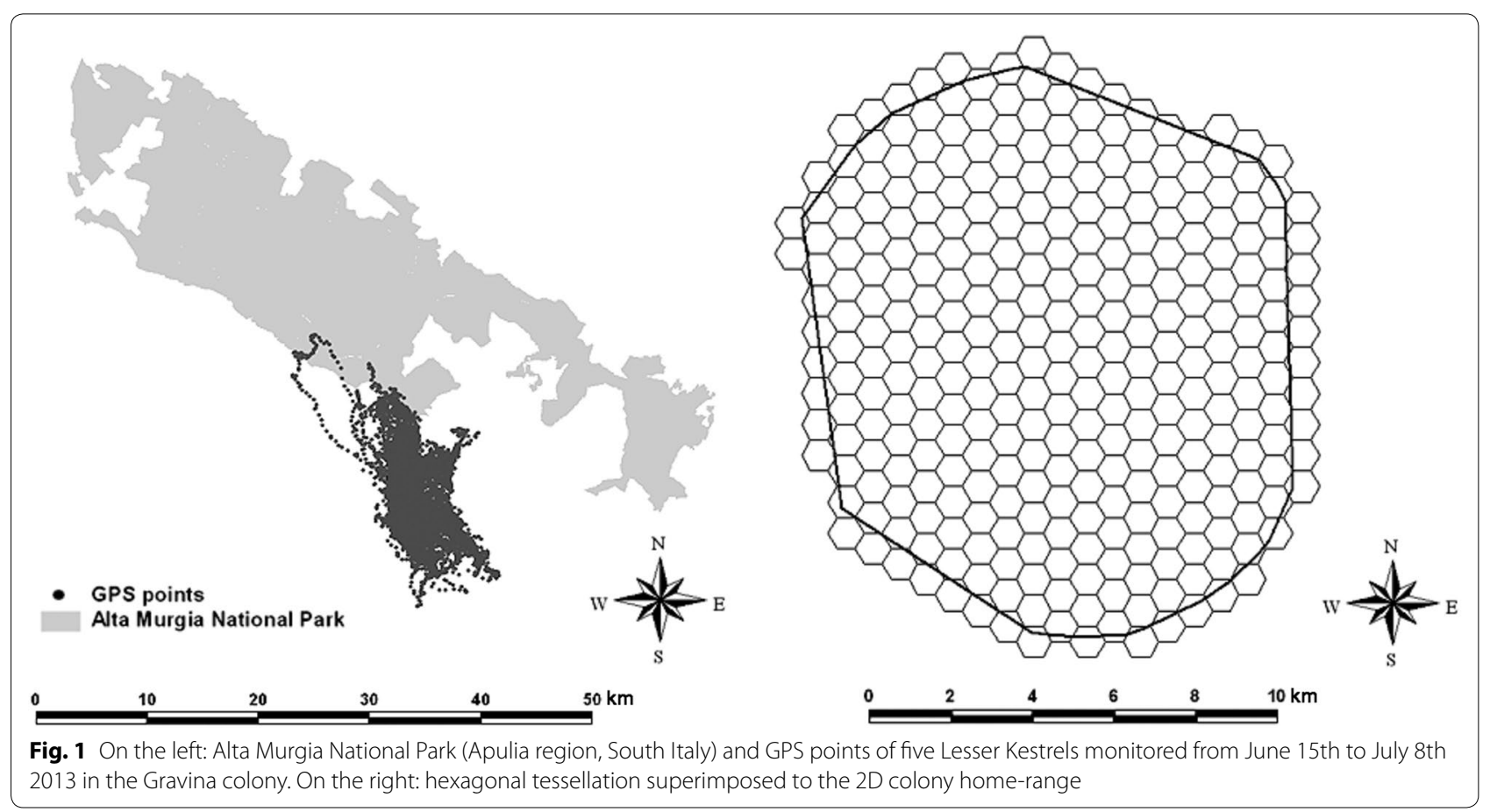


The second step consisted in the individuation of birds' 2D home range. As individual home ranges were highly overlapping (Ferrarini et al. 2018), we pooled data from all the individuals. We used percent minimum convex polygons (Michener 1979), sometimes referred to as "probability polygons" (Kenward 1987). Fixed Mean \%MCPs calculates the arithmetic mean of all $x$ (longitude) and $y$ (latitude) co-ordinates, then selects the requested percentage of points closest to that arithmetic mean point. The $95 \%$ isopleth is widely used in the literature and represented here the full 2D home range.

In the third step, we covered the 2D home range with regular, hexagonal grid. The hexagon size, determined through a trial-and-error computation, was chosen as the minimum size so that hexagons had, on average, at least 100 GPS points inside. The rationale behind this step is explained in the "Discussion" section.

In the fourth step, we assigned each GPS point to the correspondent overlapping hexagon, and for each hexagon we excluded GPS points with $H$ a.g.l. greater than the 95th percentile in order to avoid possible outliers due to anomalous fine-scale weather conditions. This step assembled the 3D home range in the form of $n$ adjacent hexagonal prisms with different heights.

In the fifth step, the volume of the Lesser Kestrels' 3D home range $\left(V_{H R}\right)$ was calculated as

$$
V_{H R}=\sum_{i=1}^{n} V_{i}=\sum_{i=1}^{n} A_{\text {hex }} * H_{\text {hex }_{i}}
$$

where $V_{i}$ is the volume of the generic $i$ th hexagonal prism, $A_{\text {hex }}$ is the hexagon size (basal area, equal for all the hexagons) and $H_{\text {hexi }}$ is the 95th percentile of $H$ a.g.l. of GPS points present within the $i$ th prism.

In the sixth step, we repeated the previous phase separately for diurnal and nocturnal GPS points. In fact, in the study area Lesser Kestrels present nocturnal flight heights that are significantly lower than during daytime (Gustin et al. 2014b, 2017b).

\section{Results}

The monitoring effort for the 5 Lesser Kestrels of Gravina in Puglia amounted to $423.8 \mathrm{~h}(n=25,405$ GPS points; Fig. 1 ). The $2 \mathrm{D}$ colony home range resulted equal to $134.86 \mathrm{~km}^{2}$, while the diurnal and nocturnal ones resulted 120.68 and $38.56 \mathrm{~km}^{2}$ respectively.

The 2D home range was covered with $3080.5-\mathrm{km}^{2}$ hexagons (Fig. 1). This hexagon size resulted the minimum size so that the average number of GPS points within each hexagon was higher than 100 (Table 1). The 95th percentile of $H$ a.g.l. resulted equal to $351 \mathrm{~m}$. The
Table 1 Results of the trial-and-error procedure employed to determine the optimal hexagon size

\begin{tabular}{lcc}
\hline Hexagon size $\left(\mathbf{k m}^{\mathbf{2}}\right)$ & Number of hexagons & $\begin{array}{l}\text { Average } \\
\text { number of GPS } \\
\text { points }\end{array}$ \\
\hline 0.1 & 1398 & 33 \\
0.25 & 584 & 58 \\
0.4 & 364 & 86 \\
0.45 & 346 & 94 \\
0.49 & 329 & 97 \\
0.5 & 308 & 104 \\
\hline
\end{tabular}

It was chosen as the minimum size so that hexagons had, on average, at least 100 GPS points inside

detected distribution of Lesser Kestrels' vertical space use is shown in Additional file 1: Fig. S3.

After the exclusion of flight heights greater than the 95th percentile, the average $H$ a.g.l. in the 310 hexagons resulted equal to $109 \mathrm{~m}( \pm 83 \mathrm{SD})$. The resulting $3 \mathrm{D}$ home range was equal to $28.12 \mathrm{~km}^{3}$ (Fig. 2). A clear pattern in the distribution of vertical space use emerged, with flight heights decreasing from the center of the home range to the border (Fig. 2).

During daytime, the average $H$ a.g.l. resulted equal to $134 \mathrm{~m}( \pm 38 \mathrm{SD})$. The diurnal 3D home range resulted equal to $33.04 \mathrm{~km}^{3}$ (Fig. 3). During night-time, the average $H$ a.g.l. resulted equal to $58 \mathrm{~m}( \pm 33 \mathrm{SD})$. The nocturnal 3D home range resulted considerably small $\left(2.84 \mathrm{~km}^{3}\right.$; Fig. 3) which was about one tenth of the overall (i.e. not split between day and night) 3D home range. Both the diurnal and nocturnal 3D home ranges confirmed the distribution of the vertical space use of the overall 3D home range, although the difference between the center of the home range and its border resulted lower in the night-time (Fig. 3).

\section{Discussion}

So far, analyses of avian space use are typically realized in $2 \mathrm{D}$, with the vertical dimension examined separately or, more often, ignored. Neglecting the $z$-dimension can severely restrains our understanding of avian space use in relation to environmental factors. Accordingly, we have proposed here a relatively-simple and computationallycheap approach to estimate time-dependent volumetric home ranges, which puts together the standard approach for $2 \mathrm{D}$ home range detection with successive consideration of third ( $z$-dimension) and, if useful, fourth (time) dimensions.

In our methodological framework, the hexagon size $\left(A_{\text {hex }}\right)$ is dependent on the number of GPS occurrences, their $x-y$ positions and $z$-values. The number of overlapping hexagons $(n)$ is dependent on both $A_{\text {hex }}$ and 


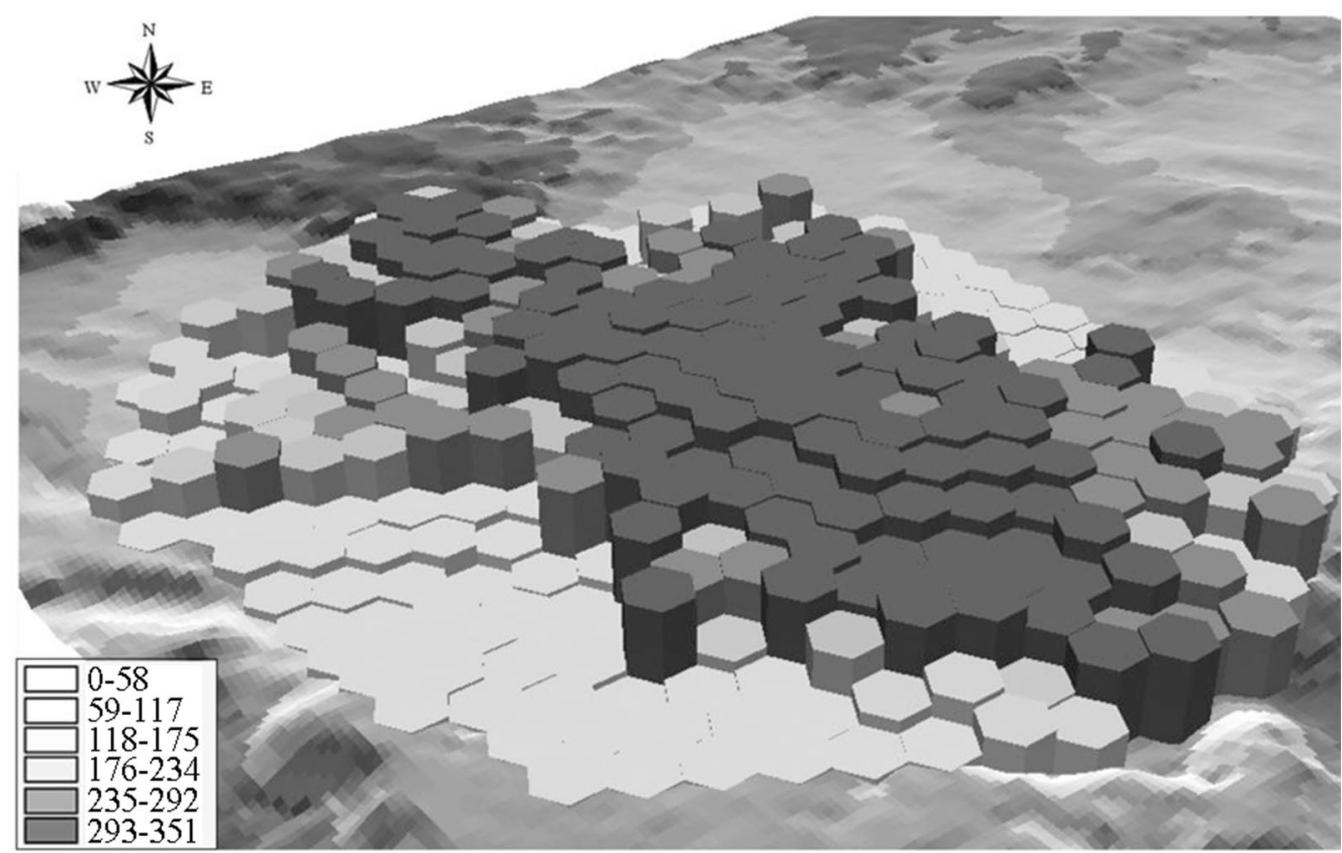

Fig. 2 3D home range $\left(28.12 \mathrm{~km}^{3}\right)$ of the Lesser Kestrels' colony of Gravina in Puglia, superimposed on the topographic map of the study area. The legend refers to heights above ground level (in $\mathrm{m}$ )

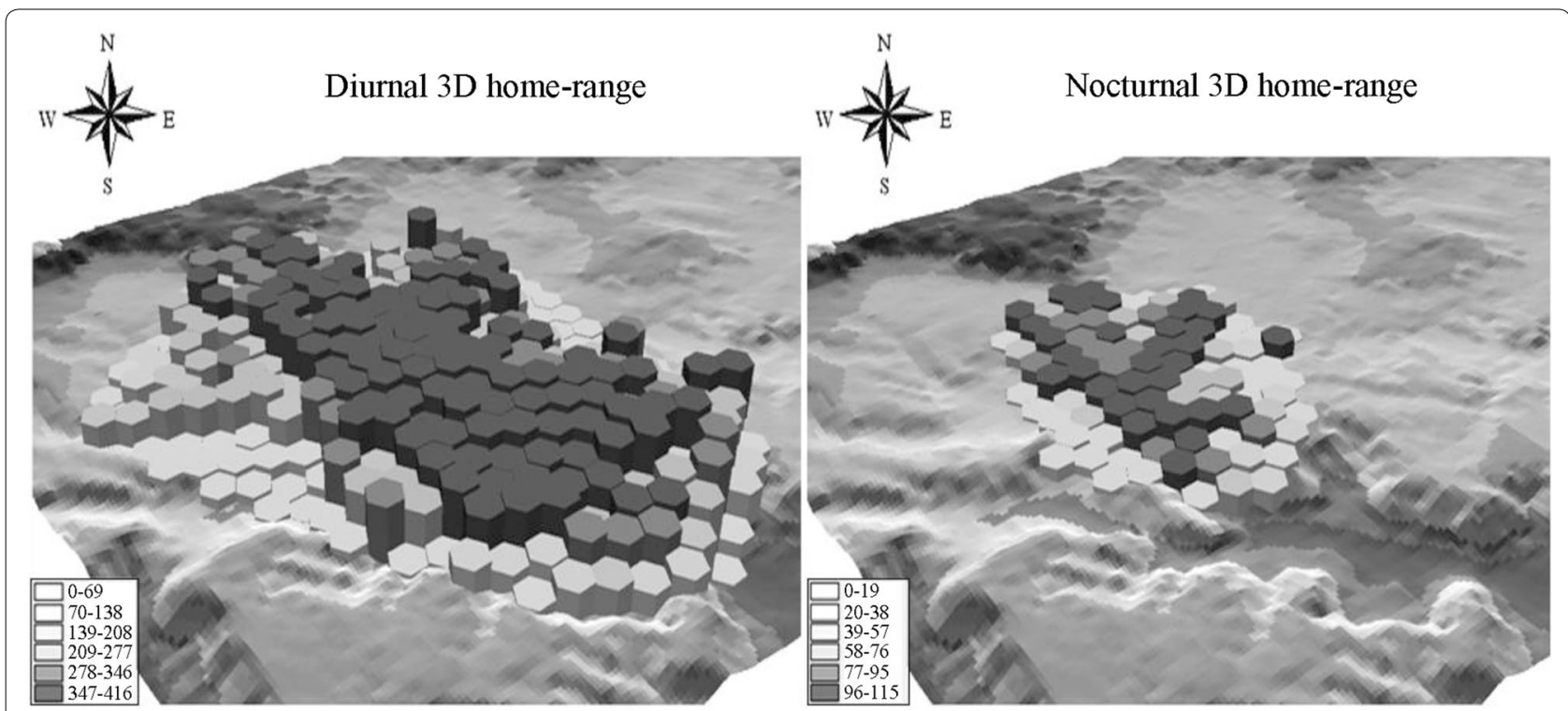

Fig. 3 On the left, diurnal 3D home range $\left(33.04 \mathrm{~km}^{3}\right)$. On the right, nocturnal 3D home range $\left(2.84 \mathrm{~km}^{3}\right)$. The legend refers to heights above ground level (in m)

the home range extension. In fact, once $A_{\text {hex }}$ is set, $n$ is approximately equal to the ratio between the detected home range and $A_{\text {hex }}$. The approximation is due to the fact that the overlapping hexagons may cover an extent which is a bit larger that the detected home range (Fig. 1). This approximation does not influence the estimation of our 3D home range, in fact if empty hexagons are present at the border of the home range, they have no $z$-values inside and thus they add no volume to the 3D home range. The choice of $A_{\text {hex }}$ as the minimum size so that hexagons had, on average, at least 100 GPS points inside was logical. In fact, with at least 100 GPS 
points per hexagon, we could exclude at least 5 GPS points having $H$ a.g.l. greater than the 95th percentile. The exclusion of flight heights above the $5 \%$ threshold of extreme statistical values was necessary to remove possible outliers due to infrequent or anomalous flight heights that could determine an oversized volumetric home range. However, we suggest to analyze the statistical distribution of $H$ a.g.l. within hexagons in order to decide if further outliers are present. In case, we suggest to use a larger hexagon size or a lower threshold (e.g., 90th percentile) in order to discard more GPS points within each hexagon. It was not our case, however this supervised step should be considered in order to generalize the application of our methodological approach.

Three regular tessellations of a plane are possible: hexagons, squares and triangles. The square tessellation is probably the most commonly used, however the hexagonal one presents several advantages (Birch et al. 2007): (1) the nearest neighbourhood in a hexagonal grid is simpler and less ambiguous than in a square grid, (2) as hexagons resemble circles, the resulting space segmentation can group GPS points in a more homogeneous way; (3) with respect to circles, hexagons present the desirable advantage that can cover the study area without empty spaces. However, we tested our volumetric home range estimator using squares as well, and results were almost identical (Additional file 1: Figs. S4, S5 and S6).

The time dimension was chosen here in terms of daytime and night-time. This was due to our previous knowledge of Lesser Kestrels' flight behaviour in the study area (Gustin et al. 2014b, 2017b). However, we argue that for other species and other study areas the time dimension could be conceived in different ways. For instance, birds could show substantial differences in space use among different intervals of the day, or among different phenological periods (breeding, nestling, pre-migration, etc.). Time could also be considered as almost continuous (e.g. hourly 3D home ranges), however we argue that some kind of discretization based on species-specific, or even colony-specific, criteria makes 3D home ranges more interesting for ecological and biological interpretations.

\section{Conclusions}

We have proposed here a new approach for the estimation of volumetric avian home ranges. Our straightforward 3D home range estimator can enhance mitigation strategies of anthropogenic impacts on bird species, by reducing the probability of false positives and negatives in environmental impact studies. It can provide more accurate estimates of collision risk with power lines (Costantini et al. 2016) and wind farms (Gustin et al. 2018) than 2D models. However, we argue that the most basic and intuitive application of our 3D home range estimator is to gain ecological insights into the volumetric requirements of birds in order to persist in their distribution areas.

\section{Additional files}

Additional file 1: Figure S1. Application of the GPS devices. Figure S2. Terrain elevation of the study area. Figure S3. Distribution of Lesser Kestrels' vertical space use. Figure S4. Alternative tessellation using 0.5$\mathrm{km}^{2}$ squares. Figure S5. Assignment of the GPS data to the tessellation squares. Figure S6. Volumetric home-range calculated through square tessellation.

Additional file 2: Table S1. Description of the tracked Lesser Kestrels.

\section{Authors' contributions}

AF designed the experiment; GG, SCP participated in the field work; AF carried out the analyses; $A F, M G$ drafted the earlier version of the manuscript and $G G$, SCP, AGF revised it. All authors read and approved the final manuscript.

\section{Author details}

${ }^{1}$ Conservation Department, LIPU - BirdLife (Lega Italiana Protezione Uccelli), Via Udine 3/a, 43122 Parma, Italy. ${ }^{2}$ Alta Murgia National Park, Via Firenze 10, 70024 Gravina in Puglia, Bari, Italy.

\section{Acknowledgements}

We thank the Editor and anonymous reviewers for their useful remarks that improved this manuscript.

\section{Competing interests}

The authors declare that they have no competing interests.

\section{Ethical standards}

Our research adheres to local guidelines and appropriate ethical approval and licences were obtained.

\section{Funding}

This work was supported by Lipu UK and the Alta Murgia National Park.

Received: 21 January 2018 Accepted: 10 May 2018

Published online: 25 May 2018

\section{References}

Birch CPD, Oom SP, Beecham JA. Rectangular and hexagonal grids used for observation, experiment and simulation in ecology. Ecol Model. 2007;206:347-59

Burt WH. Territoriality and home range concepts as applied to mammals. J Mammal. 1943:24:346-52.

Costantini A, Gustin M, Ferrarini A, Dell'omo G. Estimates of avian collision with power lines and carcass disappearance across differing environments. Anim Conserv. 2016;20:173-81.

Ferrarini A, Giglio G, Pellegrino SC, Frassanito A, Gustin M. First evidence of mutually exclusive home ranges in the two main colonies of Lesser Kestrels in Italy. Ardea 2018:106(1):1-11.

Gustin M, Ferrarini A, Giglio G, Pellegrino SC, Scaravelli D. II Parco per il Grillaio (Falco naumanni) nel Parco Nazionale dell'alta Murgia. Technical relation 2013; Lipu Press, Italy.

Gustin M, Ferrarini A, Giglio G, Pellegrino SC, Frassanito A. Detected foraging strategies and consequent conservation policies of the Lesser Kestrel Falco naumanni in Southern Italy. Proc Int Acad Ecol Environ Sci. 2014a:4:148-61. 
Gustin M, Ferrarini A, Giglio G, Pellegrino SC, Frassanito A. First evidence of widespread nocturnal activity of Lesser Kestrel Falco naumanni in Southern Italy. Ornis Fennica. 2014b;91:256-60

Gustin M, Giglio G, Pellegrino SC, Frassanito A, Ferrarini A. Space use and flight attributes of breeding Lesser Kestrels Falco naumanni revealed by GPS tracking. Bird Study. 2017a;64:274-7.

Gustin M, Giglio G, Pellegrino SC, Frassanito A, Ferrarini A. New evidences confirm that during the breeding season Lesser Kestrel is not a strictly diurnal raptor. Ornis Fennica. 2017b:94:194-9.

Gustin M, Giglio G, Pellegrino SC, Frassanito A, Ferrarini A. Nocturnal flights lead to collision risk with power lines and wind farms in Lesser Kestrels: a preliminary assessment through GPS tracking. Comput Ecol Softw. 2018;8:15-22.

Hebblewhite M, Haydon DT. Distinguishing technology from biology: a critical review of the use of GPS telemetry data in ecology. Philos Trans R Soc B. 2010;365:2303-12.
Kenward R. Wildlife radio tagging. London: Academic Press Inc.; 1987.

Negro JJ, Hiraldo F. Nest-site selection and breeding success in the Lesser Kestrel Falco naumanni. Bird Study. 1993:40:115-9.

Michener GR. Spatial relationships and social organization of adult Richardson's ground squirrels. Can J Zool. 1979;57:125-39.

TechnoSmart. GiPSy-4 manual. Micro GPS data-logger for tracking free-moving animals. Operating manual version 1.02012

Tracey JA, Sheppard J, Zhu J, Wei F, Swaisgood RS, Fisher RN. Movement-based estimation and visualization of space use in 3D for wildlife ecology and conservation. PLoS One. 2014;9:e101205.

Wang K, Franklin SE, Guo X, Cattet M. Remote sensing of ecology, biodiversity and conservation: a review from the perspective of remote sensing specialists. Sensors. 2010;10:9647-67.

Ready to submit your research? Choose BMC and benefit from

- fast, convenient online submission

- thorough peer review by experienced researchers in your field

- rapid publication on acceptance

- support for research data, including large and complex data types

- gold Open Access which fosters wider collaboration and increased citations

- maximum visibility for your research: over $100 \mathrm{M}$ website views per year

At BMC, research is always in progress.

Learn more biomedcentral.com/submissions 